\title{
A efetividade das políticas ambientais para a conservação da natureza nos parques estaduais dos Campos Gerais do Paraná1
}

\author{
La efetividad de las politicas ambientales para la conservación \\ de la naturaleza en los parques estaduales de los Campos \\ Gerais del Paraná
}

\author{
The effectiveness of environmental policies for the \\ conservation of nature in the state parks of Campos Gerais,
} Paraná

\author{
Isonel Sandino Meneguzzo \\ imeneguzzo@hotmail.com \\ Universidade Estadual de Ponta Grossa \\ Chisato Oka Fiori \\ chisato@ufpr.br \\ Universidade Federal do Paraná
}

\begin{abstract}
Resumo: O presente artigo versa sobre a efetividade das políticas ambientais nos cinco parques estaduais situados no domínio fitogeográfico dos Campos Gerais do Paraná. A metodologia empregada envolveu revisão bibliográfica, com utilização de leis, decretos e portarias emitidos pelo poder público federal e estadual, e realização de entrevistas estruturadas com os gerentes dos parques com o intuito de levantar dados sobre como as unidades de conservação são geridas tendo-se em conta a legislação ambiental vigente. Pôde-se verificar que os parques são tratados de forma distinta pelo órgão ambiental responsável por sua gestão onde as políticas ambientais não se efetivam de maneira adequada e de forma concomitante.
\end{abstract}

Palavras-chave: Políticas ambientais. Parques. Campos Gerais do Paraná.

Resumen: El presente artículo trata de la efectividad de las políticas ambientales en los cinco parques provinciales ubicados en la región del dominio fitogeográfico de los Campos Gerais del Paraná. La metodología consistió en una revisión de la bibliografía con la aplicación de las leyes, decretos y órdenes emitidas por las autoridades federales y estatales, y la realización de entrevistas estructuradas con los administradores de los parques con el fin de recopilar datos sobre cómo se gestionan áreas de conservación contra la legislación ambiental vigente. Se verificó que los parques son tratados de manera diferente por la gestión responsable de su administración ambiental cuyas las políticas ambientales no se efectúan de manera adecuada y tampoco al mismo tiempo.

Palabras clave: Política ambiental. Parques. Campos Gerais del Paraná.

1 A pesquisa foi realizada com autorização do Instituto Ambiental do Paraná: Protocolo número 321/11. 


\begin{abstract}
This article is about the effectiveness of environmental policies in the five state parks located in the region of Campos Gerais. The methodology involved a bibliographic review, including laws, decrees and orders issued by federal and state authorities and the use of structured interviews with managers of the parks in order to collect information about how the conservation areas are managed in the face of current environmental legislation. It was verified that the parks are treated differently by the management responsible for environmental agency, where environmental policies are effected inadequately and concurrently.
\end{abstract}

Keywords: Environmental policies. Parks. Campos Gerais of Paraná state.

\title{
INTRODUÇÃO
}

Os Campos Gerais paranaenses constituem uma região ímpar no contexto do estado do Paraná devido aos seus atrativos naturais, tais como rios com cachoeiras e corredeiras, relevos ruiniformes, paisagens campestres e cânions.

O patrimônio natural regional é bastante diversificado, resultado de processos geológicos, ecológicos e geomorfológicos atuantes durante milhões de anos. Essa diversidade confere aos Campos Gerais uma posição de destaque no âmbito do ecoturismo no estado do Paraná.

De uma região caracterizada por ser rota do tropeirismo dos séculos XVIII e XIX, a mesma apresenta, atualmente, uma dinâmica econômica pautada principalmente na agroindústria, na pecuária, nas atividades comerciais e na prestação de serviços. Nesse sentido, tais atividades poderiam ser pensadas em relação ao potencial natural da região, em que o desenvolvimento socioeconômico estivesse atrelado ao ecoturismo, por exemplo. Assim, os parques públicos poderiam ser utilizados como objeto de disseminação de uma sensibilização que envolvesse o conservacionismo, bem como práticas de turismo sustentáveis.

Diante desse contexto, o presente artigo trata da pesquisa que teve por intuito verificar a efetividade das políticas ambientais nos cinco parques estaduais situados nos Campos Gerais do Paraná, visando subsidiar possíveis ações por parte do governo estadual no sentido de tornar efetivas as políticas púbicas ambientais atualmente em vigência.

Aventou-se, enquanto hipótese de pesquisa, que as políticas ambientais criadas no âmbito estadual foram, ao longo do tempo, pontuais e assistemáticas.

\section{METODOLOGIA}

Visando estabelecer uma sequência sistemática de procedimentos para a consecução do objetivo proposto, o presente artigo foi concebido por meio de revisão bibliográfica envolvendo os temas das políticas ambientais no Brasil, no estado do Paraná e sobre a região dos Campos Gerais, onde os parques estaduais estão inseridos. 
A revisão teve por intuito levantar dados sobre as unidades de conservação da área objeto de estudo. As fontes pesquisadas envolveram publicações impressas variadas, sendo que consultas em sítios eletrônicos, como o do Instituto Ambiental do Paraná (IAP) e do Ministério do Meio Ambiente (MMA), também foram realizadas. Nesses sítios foram consultadas fontes primárias como leis, decretos e portarias que tratam especificamente das unidades de conservação inseridas na região dos Campos Gerais do Paraná. Num segundo momento, os dados levantados foram confrontados com a realidade de cada parque estadual inserido na região ora pesquisada para verificar a efetividade das políticas ambientais vigentes.

O levantamento dos dados relativos à efetividade das políticas ambientais atualmente em vigor e diretamente relacionadas à conservação da natureza e às unidades de conservação pautou-se nos seguintes itens: existência de conselho consultivo, existência de plano de manejo, situação fundiária, ocupação irregular, existência de mosaicos ${ }^{2}$ de unidades de conservação e atividade sistematizada de monitoramento da zona de amortecimento ${ }^{3}$. Nesse sentido, foi levado em consideração o artigo $4^{\circ}$, incisos VII e X e artigo $11, \S 1^{\circ}$, ambos da Lei Federal $n^{\circ}$ 9.985, de 18 de julho de 2000, que instituiu o Sistema Nacional de Unidades de Conservação (SNUC).

$\mathrm{O}$ artigo $4^{\circ}$ do SNUC trata dos seus objetivos, dentre os quais, especificamente no inciso VII, consta proteger as características de relevância de natureza geológica, geomorfológica, espeleológica, arqueológica, paleontológica e cultural. Já o inciso X menciona que o SNUC deve proporcionar meios e incentivos para atividades envolvendo o monitoramento ambiental (BRASIL, 2000). O artigo 11 do SNUC trata do objetivo básico de um parque que é o de conciliar preservação ambiental e o desenvolvimento de atividades envolvendo educação e interpretação ambiental e o turismo ecológico. $\mathrm{O} \S 1^{\circ}$ desse artigo determina que as áreas particulares incluídas nos limites de um parque devem ser desapropriadas (BRASIL, 2000). Outro item levado em consideração foi o artigo $27, \S 3^{\circ}$, do mesmo instrumento legal, sendo que este trata do tempo (cinco anos) em que deve ser implementado o plano de manejo de uma unidade de conservação a partir da sua criação (BRASIL, 2000).

Adicionalmente, foi levado em consideração o Decreto Federal $\mathrm{n}^{\circ} 4.340$, de 22 de agosto de 2002 (BRASIL, 2002), que trata em seu capítulo III, artigos $8^{\circ}, 9^{\circ}, 10^{\circ}$ e 11 , dos mosaicos de unidades de conservação. De acordo com esse documento, os mosaicos devem possuir um conselho de mosaico, de caráter consultivo e com a função de atuar como instância de gestão integrada das unidades de conservação que o constituem (BRASIL, 2002). De acordo com o Ministério do Meio Ambiente, o mosaico de unidades de conservação é um modelo de gestão que almeja a participação, integração e envolvimento dos gestores de unidades de conservação e da população local na gestão das mesmas, de forma a compatibilizar a presença da biodiversidade, a valorização da sociodiversidade

2 Os mosaicos foram concebidos com o objetivo de promover a integração das unidades de conservação. Essa integração pode se dar por meio da existência de corredores ecológicos, facilitando assim o fluxo gênico das espécies da fauna e da flora.

3 A zona de amortecimento é uma área situada imediatamente ao redor das unidades de conservação e tem a função de minimizar os impactos ambientais que podem vir a afetar o interior das áreas protegidas. 
e o desenvolvimento sustentável num contexto regional (MINISTÉRIO DO MEIO AMBIENTE, 2011).

Outro procedimento metodológico empregado foi o da aplicação de formulários de entrevistas ${ }^{4}$ estruturadas aos gerentes das unidades de conservação. Em relação às entrevistas, essas foram feitas com os gerentes-administradores dos parques. Foi elaborado um formulário com as questões a serem aplicadas aos gestores das unidades de conservação em que essa foi previamente construída, caracterizando-se assim como uma entrevista estruturada (MARCONI; LAKATOS, 2010). Foram elaboradas questões abertas e fechadas, com o intuito de verificar a efetividade de elementos presentes no SNUC.

O procedimento de aplicação dos formulários foi realizado no mês de setembro de 2012 e contou com a assinatura de termo de consentimento livre e esclarecido por parte das pessoas submetidas a esse procedimento.

Os formulários de entrevistas foram aplicados aos três gerentes das cinco unidades de conservação pesquisadas, considerando que o Parque Estadual de Vila Velha, o Parque Estadual do Cerrado e o Parque Estadual do Vale do Codó são gerenciados por uma mesma pessoa.

\section{AS POLÍTICAS AMBIENTAIS NO BRASIL}

No Brasil, a formulação e implementação das políticas ambientais estiveram ligadas ao contexto histórico e político do país. A própria formação social do Brasil sugere isso, pois tal como aponta Ferreira (1996), os mais importantes elementos que caracterizam o processo de formação social são a hierarquia, o paternalismo, a repressão e o autoritarismo. Moraes (2002) complementa incluindo também o patrimonialismo, dizendo que o estado nacional é um aparelho político dos proprietários de terra ${ }^{5}$, considerando-o assim como uma extensão de suas propriedades.

Durante o período em que o país viveu sob o regime militar, as políticas ambientais entram em contradição com as políticas modernizantes e de integração nacional implementadas pelo poder público federal (CUNHA; COELHO, 2009). Ainda sobre o período da ditadura militar, Diegues (2000) ressalta que as áreas protegidas e as políticas públicas que envolviam o meio ambiente eram decididas e impostas sem consulta à população em geral, como, aliás, era feito para as demais políticas públicas. Portanto, somente a partir do ano de 1985 é que a participação popular voltou a existir em âmbito nacional com a redemocratização do país.

Cunha e Coelho ainda comentam que:

Depois de um período em que as iniciativas de regulação estiveram fortemente centralizadas junto às instituições governamentais, o cenário das décadas de 1980 e 1990

4 O formulário de entrevista foi submetido ao Comitê de Ética em Pesquisa das Faculdades Integradas dos Campos Gerais (protocolo número 877/CEP), conforme estabelece a legislação que trata de pesquisa envolvendo seres humanos.

5 A tese de Albuquerque (2007) traz à tona elementos contundentes de que nos Campos Gerais do Paraná "os donos da terra" são os latifundiários e as cooperativas agroindustriais impõem a forma de apropriação e exploração do espaço regional. 
foi sendo crescentemente marcado pela busca de modelos alternativos de participação da sociedade civil nos processos de tomada de decisão de políticas e também na implementação de programas e projetos com caráter ambiental. (CUNHA; COELHO, 2009, p. 67).

De acordo com Cunha e Coelho (2009), a partir da década de 1980, o processo de formulação e implementação da política ambiental no Brasil passou a ser, cada vez mais, resultado da interação entre ideias, valores e estratégias de ação de diferentes atores sociais, num campo marcado por contradições, alianças e conflitos que emergem da multiplicidade de interesses envolvidos com a problemática da proteção do meio ambiente. Fatores como a democratização dos processos de tomada de decisão, a ampliação da participação da sociedade civil na resolução dos problemas ambientais e a descentralização das atividades de monitoramento e fiscalização contribuíram para que houvesse uma dinamização dos processos de gestão ambiental no país. Segundo os autores acima citados, as mudanças significativas ocorreram efetivamente após a promulgação da Constituição Federal de 1988. O envolvimento das sociedades locais em relação às questões socioambientais, culturais, econômicas e políticas passou a ser estimulado. As noções de divisão de responsabilidade e de complementaridade entre as competências federais, estaduais e municipais ganharam importância e foram acompanhadas de discussões sobre o papel dos diversos atores sociais na reformulação das políticas públicas.

Philippi Junior, Bruna e Silveira (2005) veem as políticas ambientais de uma forma diferenciada. Para eles, a gestão integrada dos recursos naturais se consubstanciou por meio de um marco histórico ambiental memorável: a Política Nacional de Meio Ambiente (PNMA) - Lei Federal número 6.938, de 31 de agosto de 1981. Essa lei estabelece como princípio básico e fundamental a importância institucional do Estado no que tange a manutenção do equilíbrio ecológico.

Souza (2005) argumenta que, no Brasil, as políticas ambientais podem ser vistas sob três óticas, as quais estão cronologicamente assim dispostas: a ótica corretiva, preponderante na década de 1970; a de caráter preventivo, vigente na década de 1980, e a última, integradora, que se inicia após a década de 1990. Ainda conforme essa mesma autora, até a década de 1990, as medidas possuíam a característica de serem setoriais e o meio ambiente era visto como um acessório do desenvolvimento industrial implantado no país a partir de 1960. Para Souza (2005), a política ambiental no Brasil se desenvolveu de forma tardia se comparada com outras políticas setoriais, e basicamente em resposta às exigências do movimento ambientalista internacional.

Portanto, no Brasil, as políticas ambientais começaram a ser elaboradas e implementadas de forma mais consistente com a promulgação da Lei n ${ }^{\circ} 6.938 / 81$, de seu decreto regulamentador de 1990 e com a Constituição Federal de 1988, segundo a qual o Estado tem a função de promover a conservação ambiental, a fiscalização e a gestão ambiental.

Neste sentido, ao diagnosticar a política ambiental brasileira, Lima (2011) expõe que essa ainda padece de falta de vontade e prioridade política por parte dos representantes políticos, que a fragmentação entre os diferentes setores do governo ainda existe, que ainda há a necessidade da participação legítima da sociedade, que a incoerência existente 
entre as leis e as práticas está presente e que a ambiguidade estatal diante dos interesses de caráter privado prevalece.

Deve-se mencionar o fato de que, nos últimos anos, surgiram, no âmbito legal, os conselhos municipais e estaduais de meio ambiente, bem como a forte atuação de Organizações Não-Governamentais (ONGs) como importantes agentes sociais presentes nas discussões, na formulação e aplicação das políticas ambientais.

O contexto de que emerge essa nova forma de gestão ambiental é o da crise fiscal que o país sofreu durante a década de 1980 (LIMA, 2011). Para esse mesmo autor, a descentralização política (e, consequentemente, a ampliação da democracia) surge como uma alternativa para que haja a diminuição da responsabilidade do Estado, em que esse é afetado economicamente em relação às crescentes demandas provenientes da sociedade.

Especificamente em relação à criação de parques no Brasil, o primeiro a ser criado foi em 1937, em Itatiaia, estado do Rio de Janeiro. Desde sua criação, parques com objetivos distintos foram sendo implementados no Brasil. Da década de 1930 até os dias atuais, a criação desses parques não obedeceu a nenhuma preocupação única e, dessa forma, os mesmos foram implementados em momentos históricos distintos e abrangendo diferentes biomas, sendo que alguns não foram devidamente priorizados.

A partir da promulgação da Constituição Federal de 1988 é que começou a se pensar numa normatização e categorização das unidades de conservação no Brasil. Desse momento até por volta do ano 2000, diversos debates ocorreram para que fosse criada uma legislação nacional que pudesse ser aplicada às áreas protegidas. Cabe destacar que uma série de eventos (convenções e assembleias) em escala mundial e continental contribuíram para o estabelecimento de conceitos e diretrizes referentes às unidades de conservação em nível mundial (VALLEJO, 2009). Nesse sentido, a União Internacional para Conservação da Natureza (UICN) tem contribuído para a internacionalização do debate sobre áreas protegidas, pois categoriza as mesmas com base em critérios científicos, sendo referência para a criação de sistemas nacionais de áreas protegidas (CASTRO JÚNIOR; COUTINHO; FREITAS, 2009).

A criação de parques em várias partes do mundo, incluindo o Brasil, seguiu o modelo preservacionista norte-americano do Parque Nacional de Yellowstone (DIEGUES, 2000).

No Brasil, somente no ano de 2000 é que o Sistema Nacional de Unidades de Conservação (SNUC) foi promulgado, estabelecendo uma padronização de áreas protegidas para todo o território nacional. Dois anos mais tarde, foi publicado o Decreto Federal número 4.340, de 22 de agosto de 2002. Constam nesse decreto que no ato de criação de uma unidade de conservação deve haver a indicação da denominação da mesma, sua categoria de manejo, os objetivos, os limites, a área da unidade e o órgão ambiental responsável por sua gestão (BRASIL, 2002). Traz também a regulamentação referente aos mosaicos de unidades de conservação, observações sobre a elaboração de plano de manejo e da gestão compartilhada por OSCIP (Organização da Sociedade Civil de Interesse Público), dentre outras informações (BRASIL, 2002).

No ano de 2010 foi publicada a Portaria número 482, do Ministério do Meio Ambiente, regulamentando as atividades de criação dos Mosaicos de Unidades de Conserva- 
ção no Brasil. Os mosaicos constituem um modelo de gestão em que a participação social se faz necessária e obrigatória para que todas as medidas relacionadas às unidades de conservação e regiões circunvizinhas sejam pensadas em conjunto.

Especificamente em relação às UCs paranaenses, essas se encontram aleatoriamente distribuídas no contexto dos diferentes ecossistemas. O critério adotado para a preservação e conservação por meio da criação de unidades de conservação foi ocorrendo aleatoriamente ao longo do tempo e apenas o fator de que esses eram remanescentes vegetacionais com poucas alterações antrópicas serviu para a gênese dessas unidades.

A partir de fins da década de 1970, passou-se a trabalhar as unidades de conservação tendo como enfoque prioritário o manejo de áreas silvestres (HASSLER, 2006), sendo que esse procedimento vem sendo desenvolvido por parte do poder público estadual ainda nos dias atuais.

Somente após 1995 é que se começou a enfatizar a questão da regularização fundiária das unidades de conservação (HASSLER, 2006), sendo que inúmeras áreas protegidas ainda estão com pendências em relação às sua situação fundiária.

Nos Campos Gerais do Paraná, o estabelecimento dos parques ocorreu em diferentes contextos políticos e históricos. O surgimento das UCs deu-se por diferentes objetivos diante de circunstâncias ambientais também diferenciadas face à evolução das políticas ambientais brasileiras, as quais influenciaram as unidades da federação em relação à implementação de áreas protegidas (MENEGUZZO, 2013).

Cabe destacar que, atualmente, as verbas referentes à gestão econômico-financeira das UCs paranaenses estão vinculadas ao Fundo Estadual do Meio Ambiente, instituído pela Lei Estadual número 12.945, de 05 de setembro de 2000. As UCs contam também com verbas provenientes de medidas compensatórias de empreendimentos que causam significativos impactos ambientais negativos. Nesse sentido, o empreendedor é obrigado a apoiar a implantação e manutenção de UCs tal como estabelece o artigo 36 do SNUC (BRASIL, 2000) e seu Decreto Regulamentador no artigo 10, inciso II.6 (BRASIL, 2002).

\section{OS CAMPOS GERAIS DO PARANÁ E SUAS PAISAGENS}

Apesar de consagrada pelo geógrafo e geólogo Reinhard Maack em sua obra intitulada Notas sobre clima, solos e vegetação do Estado do Paraná, datado de 1948, a expressão Campos Gerais do Paraná já vinha sendo utilizada há muitos anos, tal como atestam os relatos de Auguste de Saint-Hilaire (SAINT-HILAIRE, 1978) e até mesmo do imperador Dom Pedro II (SANTOS, 2008), quando de suas passagens pela região no século XIX.

Os Campos Gerais compreendem uma zona fitogeográfica de predomínio de campos, tecnicamente enquadrada como Estepe Gramíneo-Lenhosa (VELOSO; RANGEL FILHO; LIMA,1991) com a ocorrência de cerrados e matas ciliares ao longo dos rios e arroios, e de capões isolados com a presença do pinheiro de araucária, numa extensão original aproximada de $19.060 \mathrm{~km}^{2}$ (MAACK, 1948). A região está localizada (Figura 1) no segmento leste do Segundo Planalto Paranaense, no reverso do degrau topográfico da 
Escarpa Devoniana (MELO; MENEGUZZO, 2001). Apresenta suaves elevações de topo de planalto que se estendem desde Rio Negro, no limite com Santa Catarina, ao sul, até Sengés, no limite com São Paulo, ao norte.

Figura 1 - Mapa de localização dos Campos Gerais do Paraná

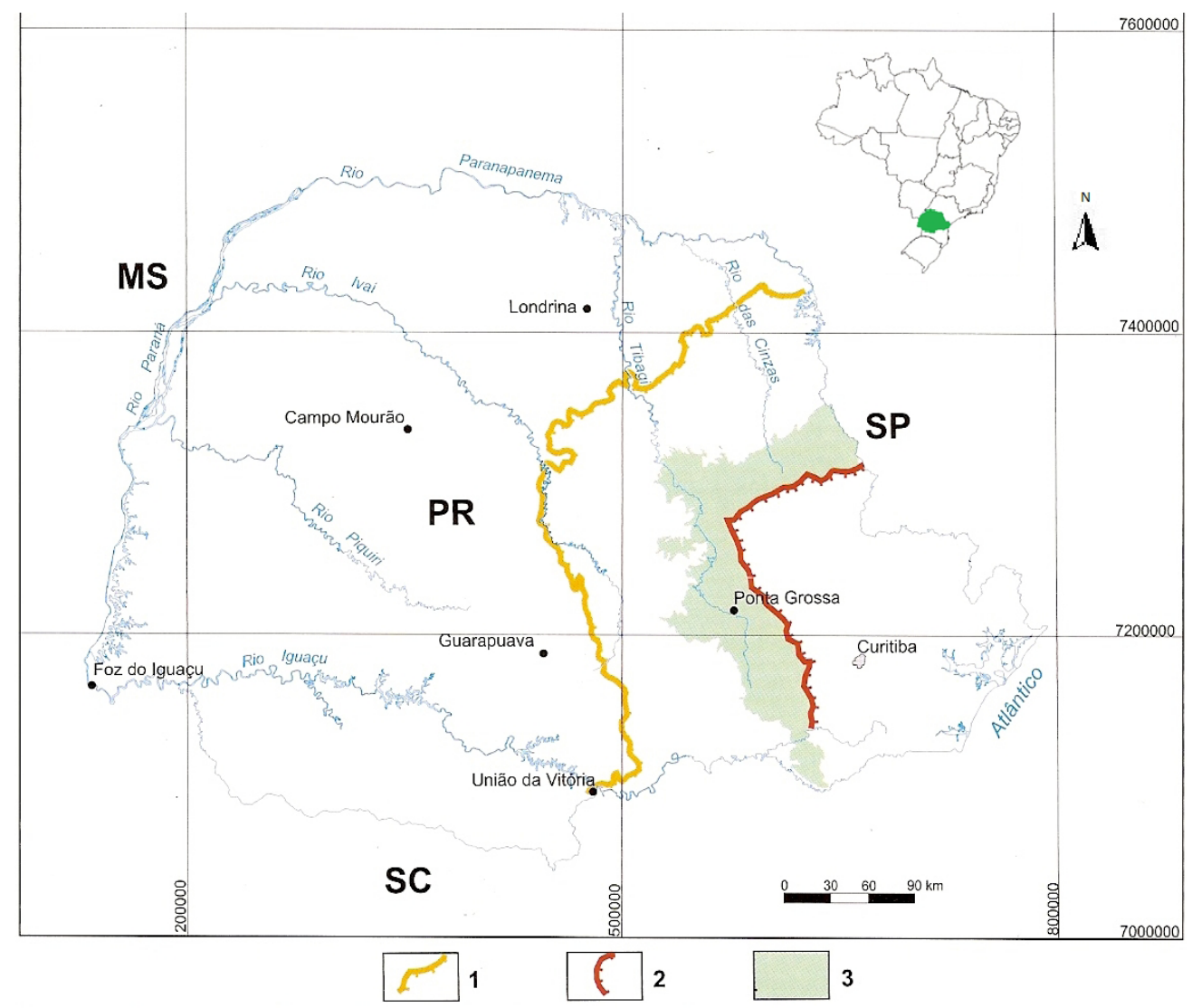

Legenda: 1: Escarpa Triássico-Jurássica; 2: Escarpa Devoniana; 3: Limite dos Campos Gerais do Paraná. Modificado de: Melo; Meneguzzo (2001)

A região possui sítios naturais com escarpamentos, cânions, relevos ruiniformes, remanescentes de vegetação de campos (Estepe Gramíneo-Lenhosa), de florestas (Floresta Ombrófila Mista) e cerrado. Assim, a paisagem regional apresenta atrativos de interesse ecoturístico devido a sua geodiversidade e biodiversidade, fruto da interação entre o meio biótico e abiótico, no decorrer de milhões de anos.

Apesar de apresentar inúmeras belezas naturais, a região vem sofrendo há séculos com os processos de impactos ambientais (desmatamento, queimadas, processos erosivos, entre outros), o que descaracterizou significativamente a paisagem regional, bem como promoveu a fragmentação de ecossistemas.

\section{RESULTADOS E DISCUSSÃO}

Nos Campos Gerais do Paraná existem, sob a égide da legislação ambiental estadual, cinco parques estaduais (Figura 2), dos quais três são administrados pelo IAP e dois pela ECOPARANÁ. 
Figura 2 - Parques estaduais situados nos Campos Gerais do Paraná

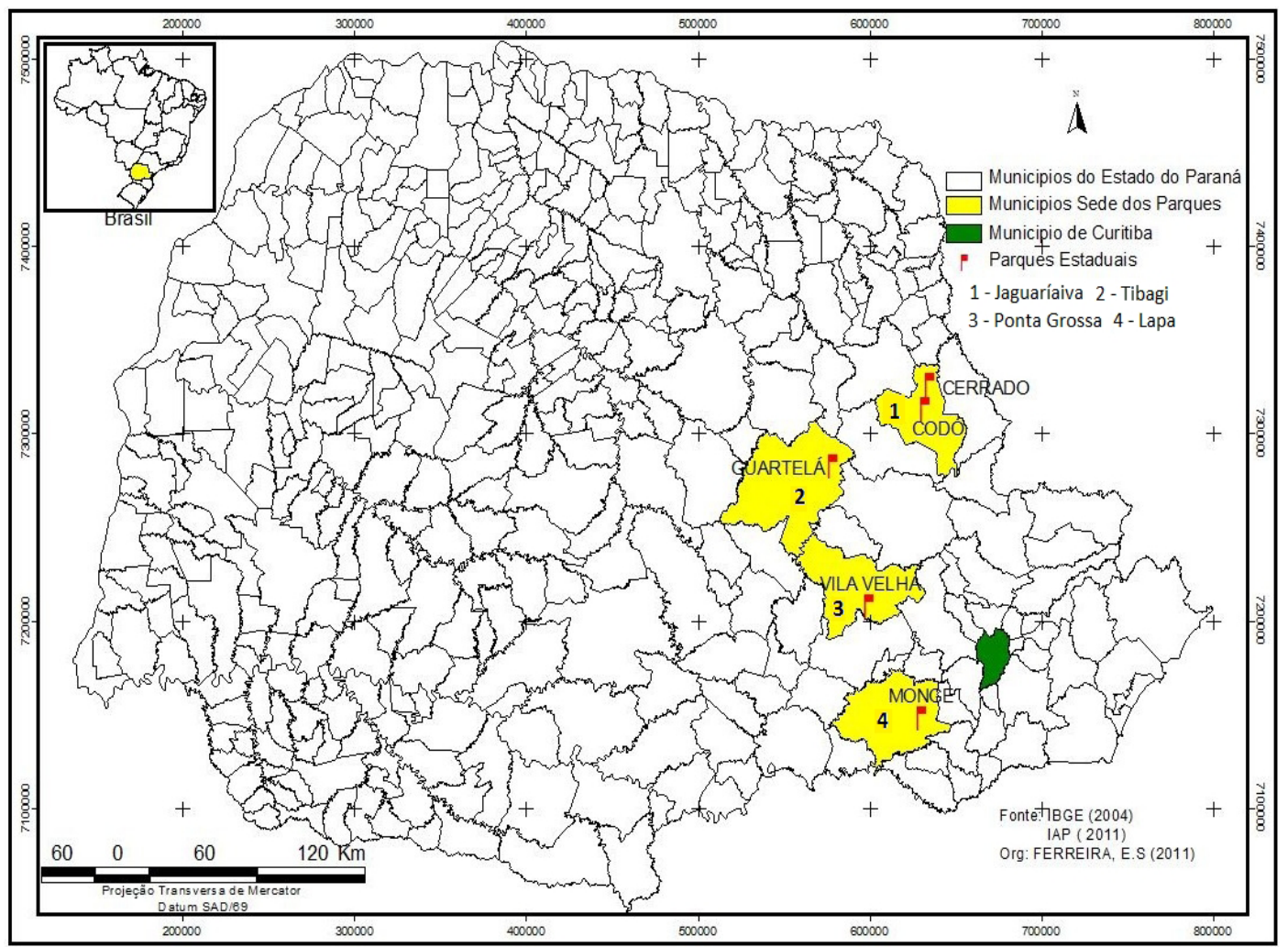

Elaboração: Ferreira, E. S. (2011)

As Unidades de Conservação estaduais existentes nos Campos Gerais do Paraná são tratadas, a seguir, levando em consideração aspectos presentes na Lei número 9.985, de 2000, e no Decreto número 4.340, de 2002.

- Parque Estadual de Vila Velha (PEVV): O PEVV situa-se no município de Ponta Grossa e desde meados de 2013 sua administração passou do Instituto Ambiental do Paraná (IAP) para a ECOPARANÁ, órgão vinculado à Secretaria de Estado do Turismo.

A unidade possui um conjunto de formações areníticas de expressivo valor cênico, científico e ambiental (MOREIRA; ROCHA, 2007). Em conjunto com as formações geológico-geomorfológicas, as Furnas e a Lagoa Dourada constituem os principais atrativos do parque. Além desses elementos, apresenta remanescentes de Floresta Ombrófila Mista e vegetação de campos.

Sob o aspecto legal, o parque foi instituído pela Lei número 1.292, de 10 de fevereiro de 1953 (PARANÁ, 1953). Inicialmente possuía uma área de 3.122,11 hectares, sendo que atualmente possui $3.803,28$ hectares. Sua área foi ampliada por meio do Decreto número 5.767, de 05 de junho de 2002 (PARANÁ, 2002).

O PEVV foi criado com duas finalidades: a de conservar remanescentes florestais e a de estimular a atividade do turismo. Nesse contexto, ressalta-se que a vegetação de campos e as feições geológico-geomorfológicas do mesmo, incluindo as Furnas e a Lagoa Dourada, foram deixadas de lado enquanto objetos de conservação. 
Somente no ano de 1955 é que o PEVV foi realmente efetivado, constituindo no mais antigo parque sob legislação estadual do Paraná (HASSLER, 2006).

Seu Conselho Consultivo foi criado pela Portaria número 178, de 31 de agosto de 2004 (PARANÁ, 2004). Em relação ao plano de manejo, o mesmo foi efetivado por meio da Portaria número 37, de 17 de fevereiro de 2004 (MINISTÉRIO DO MEIO AMBIENTE, 2004).

Em relação à situação fundiária e a ocupações irregulares, o mesmo não apresenta nenhum tipo de problema, segundo entrevista realizada com a gerente da unidade.

No tocante ao monitoramento da zona de amortecimento, a gestora da unidade respondeu que o parque ainda não possui um monitoramento sistemático, sendo esse procedimento realizado de forma aleatória.

- Parque Estadual do Guartelá (PEG): Situa-se no município de Tibagi. Possui como atrativos naturais as paisagens singulares com cachoeiras, os ecossistemas de campos, cerrados, Floresta Ombrófila Mista, Floresta Estacional Semidecidual (MOREIRA; ROCHA, 2007) e lapas, algumas das quais guardam vestígios arqueológicos. Tem uma área total de 798,97 hectares e as amplitudes altimétricas podem superar os 450 metros (MELO, 2011), região em que o rio Iapó escavou um cânion com paredes abruptas em rochas da Formação Furnas. Possui também uma elevada riqueza florística, consequência das diversas formas fisionômicas (CARMO, 2006), o que também contribui como um atrativo de natureza ecoturística.

A unidade teve sua proteção efetivada por meio do Decreto Estadual número 2.329, de 24 de setembro de 1996 (PARANÁ, 1996).

De acordo com seu ato de criação, o objetivo do PEG é o de: “[...] assegurar a preservação de ecossistemas típicos, locais de excepcional beleza 'cênica' como cânions e cachoeiras, além de significativo patrimônio espeleológico, arqueológico e pré-histórico, em especial pinturas rupestres." (PARANÁ, 1996).

O Conselho Consultivo do PEG foi implementado somente em 2002, por meio da Portaria número 143, do dia 30 de julho (PARANÁ, 2002), ou seja, cinco anos após a efetiva implantação da unidade. Já em relação ao plano de manejo, o mesmo foi finalizado e posto em prática também no ano de 2002.

Desde a publicação de seu ato de criação, o Estado tentou adequar a área do PEG em relação à sua situação fundiária. Atualmente, de acordo com entrevista realizada com o gerente da unidade de conservação, o parque está totalmente regularizado e não possui nenhum tipo de ocupação irregular.

No cadastro nacional de unidades de conservação, disponível no sítio eletrônico do Ministério do Meio Ambiente, não aparecem informações sobre o plano de manejo dessa unidade de conservação. Porém, no sítio eletrônico do IAP consta que este foi implementado no ano de 2002, informação confirmada por meio de entrevista junto ao gerente do parque.

Em relação à zona de amortecimento da unidade, o gestor da mesma ressaltou que não existem atividades sistematizadas de monitoramento. Porém, visitas esporádicas e em pontos aleatórios da zona de amortecimento são realizadas com vistas a identificar 
possíveis atividades que não estejam em consonância com os objetivos do parque e seu plano de manejo.

- Parque Estadual do Cerrado (PEC): Localiza-se entre os municípios de Jaguariaíva e Sengés. Possui uma área de 1.830,40 hectares.

É uma das poucas áreas de conservação da região formada predominantemente por formações savânicas que variam do campo limpo a campo sujo, passando pelo campo cerrado, cerrado stricto sensu até o cerradão (TAKEDA; MATTOSO TAKEDA; FARAGO, 2001).

De acordo com Paraná (1992) a unidade surgiu com o objetivo de “[...] preservar os campos cerrados, ecossistema típico e em vias de extinção, bem como locais de excepcional beleza cênica, como cânions e cachoeiras".

O parque foi criado em 1992 por meio da Lei número 1.232, do dia 27 de março (PARANÁ, 1992), e ampliado pelo Decreto número 1.527, de 02 de outubro de 2007 (PARANÁ, 1992). Seu plano de manejo foi aprovado pela Portaria número 217, de 19 de dezembro de 2002 (MINISTÉRIO DO MEIO AMBIENTE, 2002).

Apesar de haver um decreto que estabelece a ampliação da área do parque, na prática isso ainda não aconteceu. De acordo com entrevista realizada com a gerente da unidade, a mesma respondeu que os procedimentos legais visando à efetivação dessa medida ainda não ocorreram em sua totalidade.

O parque ainda não teve a implementação de seu conselho consultivo.

- Parque Estadual do Monge (PEM): O PEM está situado no município da Lapa. A unidade de conservação possui uma área de 297,83 hectares e atualmente é gerida pela ECOPARANÁ.

Ainda que apresente áreas de mata alteradas e reflorestamentos, abrange uma região de campos limpos, os chamados Campos da Lapa, com capões associados a florestas de galeria profundamente antropizados (MOREIRA; ROCHA, 2007). Entretanto, em sua criação também foram considerados os atrativos naturais da Gruta do Monge e da cachoeira da Pedra Partida.

A unidade de conservação foi criada por meio da Lei número 4.170, de 22 de fevereiro de 1960 (PARANÁ, 1960), e do Decreto número 6.351, de 23 de fevereiro de 1979 (PARANÁ, 1979). Efetivamente, o PEM foi instituído ao longo das décadas de 1960 e 1970, quando da realização de diversas desapropriações. Portanto, de forma efetiva, somente em 1979 o parque teve sua consolidação em termos legais.

Seu conselho consultivo foi implementado a partir da publicação da Portaria número 24, de 02 de março de 2009 (PARANÁ, 2009).

De acordo com o gerente do parque, o mesmo possui ocupações irregulares e sua situação fundiária encontra-se em processo de regularização. Em relação à zona de amortecimento, o gerente da unidade respondeu que o mesmo não possui monitoramento sistemático dessa área relacionada à unidade de conservação.

- Parque Estadual do Vale do Codó (PEVC): O PEVC situa-se no município de Jaguariaíva e possui uma área de 760 hectares. 
Em seu perímetro ocorrem remanescentes de vegetação de campos associados a matas ciliares que circundam as margens do rio Jaguariaíva. Além disso, esse rio forma um vale bastante amplo com paredes abruptas e afloramentos do arenito Furnas.

Foi criado por meio do decreto estadual número 1.528 de 02 de outubro de 2007 (PARANÁ, 2007). Tem como objetivo geral:

[...] a preservação dos ecossistemas naturais abrangidos, pela sua relevância ecológica e beleza cênica, possibilitando, dentro das diretrizes apontadas no Plano de Manejo, a realização de pesquisas científicas, de atividades de conscientização, educação e interpretação ambientais e de turismo sustentável e de recreação em contato com a natureza. (PARANÁ, 2007).

O objetivo geral da unidade vem em direção favorável à tendência mundial que envolve tanto a conservação da natureza como da possibilidade de desenvolvimento de atividades antrópicas levando em consideração os aspectos técnico-jurídicos, bem como os preceitos do desenvolvimento sustentável. Além disso, o decreto traz ainda objetivos específicos em relação à unidade de conservação:

São objetivos específicos do PARQUE a preservação de campos nativos, campos rupestres, cerrado e ecossistemas associados, além dos remanescentes de Floresta Ombrófila Mista ou Floresta de Araucária, as paisagens de alto alcance e os mirantes naturais com grande amplitude visual, os recursos hídricos, em especial as quedas d'água e cachoeiras, as fontes e nascentes, os paredões e afloramentos de arenito relictos da Era Devoniana ${ }^{6}$, o Cânion do rio Jaguariaíva, bem como a integração entre o Primeiro e o Segundo Planaltos do Paraná através de Corredor de Biodiversidade que possibilite o fluxo gênico, o trânsito da fauna silvestre e a salvaguarda dos pontos de parada e reprodução da avifauna. (PARANÁ, 2007).

Por ter sido publicado em 2007, o decreto estadual que cria o PEVC traz em seus objetivos específicos elementos consistentes para uma conservação da natureza com um caráter holístico. Ou seja, não prioriza apenas elementos bióticos e, sim, traz em seu conteúdo a percepção de que existe a necessidade de se preservar elementos da flora, da fauna, do substrato rochoso, de feições geomorfológicas e dos recursos hídricos.

$\mathrm{O}$ instrumento legal que cria o PEVC determina que num prazo de cinco anos, a contar a data de publicação do decreto, a unidade deverá ter um plano de manejo elaborado (PARANÁ, 2007). Consta ainda nesse documento que a unidade deve possuir um Conselho Consultivo, o qual já deveria ter sido constituído pelo IAP.

Dessa forma, o PEVC ainda não possui conselho consultivo nem plano de manejo instituídos. Sua situação fundiária encontra-se em regularização, de acordo com resposta obtida junto à gestora da unidade. O parque não possui ocupações irregulares em seu perímetro e também não possui monitoramento sistemático em sua zona de amortecimento.

6 O correto é período Devoniano e não Era Devoniana. Na escala do tempo geológico, o período Devoniano está situado na Era Paleozoica. 
Com o intuito de sintetizar todos os dados levantados por meio da pesquisa, foi elaborado o quadro a seguir (Quadro 1). Nele constam elementos que permitem verificar de forma didática a efetividade da política ambiental em relação aos parques estaduais situados na região objeto de estudo.

Quadro 1 - Síntese dos aspectos da efetividade das políticas ambientais nos Campos Gerais do Paraná.

\begin{tabular}{|l|l|l|l|l|l|l|l|l|l|}
\hline Parque & $\begin{array}{l}\text { Ano do } \\
\text { ato legal } \\
\text { de criação }\end{array}$ & $\begin{array}{l}\text { Ano de } \\
\text { implementação } \\
\text { do Parque }\end{array}$ & $\begin{array}{l}\text { Conselho } \\
\text { Consultivo }\end{array}$ & $\begin{array}{l}\text { Ano de Implantação } \\
\text { do Conselho } \\
\text { Consultivo }\end{array}$ & $\begin{array}{l}\text { Plano de } \\
\text { manejo }\end{array}$ & $\begin{array}{l}\text { Ano de } \\
\text { implementação } \\
\text { do plano } \\
\text { de manejo }\end{array}$ & $\begin{array}{l}\text { Situação } \\
\text { fundiária }\end{array}$ & $\begin{array}{l}\text { Mosaico } \\
\text { de UC }\end{array}$ & $\begin{array}{l}\text { Monitoramento } \\
\text { da Zona de } \\
\text { Amortecimento }\end{array}$ \\
\hline Vila Velha & 1953 & 1955 & Sim & 2004 & Sim & 2004 & Regular & Não & Não \\
\hline Guartelá & 1996 & 1997 & Sim & 2002 & Sim & 2002 & Regular & Não & Não \\
\hline Cerrado & 1992 & 2001 & $\begin{array}{l}\text { Não } \\
\text { possui }\end{array}$ & Não possui & Sim & 2002 & $\begin{array}{l}\text { Em } \\
\text { regularização }\end{array}$ & Não & Não \\
\hline $\begin{array}{l}\text { Vale do } \\
\text { Codó }\end{array}$ & 2007 & $\begin{array}{l}\text { Não } \\
\text { implementado }\end{array}$ & $\begin{array}{l}\text { Não } \\
\text { possui }\end{array}$ & Em formação & $\begin{array}{l}\text { Não } \\
\text { possui }\end{array}$ & $\begin{array}{l}\text { Não } \\
\text { implementado }\end{array}$ & Irregular & Não & Não \\
\hline Monge & 1960 & 1979 & Sim & 2009 & Sim & 2002 & $\begin{array}{l}\text { Em } \\
\text { regularização }\end{array}$ & Não & Não \\
\hline
\end{tabular}

Fonte: IAP (2011); MMA (2011a); MMA (2011b); Entrevistas (2011).

Organização própria (2013).

\section{CONSIDERAÇÕES FINAIS}

Pôde-se verificar que as unidades de conservação ora pesquisadas não vêm sendo geridas de uma forma adequada. Os parques não atendem a alguns princípios presentes na legislação ambiental vigente, o que, consequentemente, vem comprometendo a conservação dos elementos naturais dos parques inseridos na região dos Campos Gerais do Paraná.

A partir da constatação de ausência de conselho consultivo, de plano de manejo, de situação fundiária irregular (ou ainda em regularização), de existência de ocupações irregulares e de ausência de monitoramento sistemático em zonas de amortecimento dos parques, constata-se que atualmente existem pendências a serem resolvidas por parte do poder público estadual em relação à efetividade das políticas ambientais vigentes. Esses constituem problemas de ordem técnica e administrativa que, se solucionados, certamente contribuirão para a conservação da natureza nos parques pesquisados.

Com a existência do SNUC, de seu decreto regulamentador e do IAP, a estrutura organizacional do Estado permite com que políticas públicas sejam formuladas e implementadas visando à conservação da natureza numa perspectiva integrada. Dessa maneira, os elementos bióticos e abióticos podem ser levados em consideração de forma equânime, contribuindo assim para sua efetiva conservação.

Apesar do arcabouço legal estabelecer a integração entre as políticas ambientais, nos diferentes níveis (federal e estadual), esse fato não vem acontecendo de forma efetiva nos parques estaduais pesquisados. Exemplo disso pode ser dado a partir da publicação do Decreto 4.340, de 2002. Nota-se a morosidade em regulamentar os instrumentos 
legais, o que de certa forma prejudica a gestão de espaços legalmente protegidos e, consequentemente, a conservação adequada desses. Até o momento nenhuma iniciativa foi tomada para se efetivar um Conselho de Mosaico envolvendo as unidades de conservação no contexto dos Campos Gerais do Paraná. Portanto, a existência de políticas ambientais sinaliza apenas para o seu reconhecimento político e importância no plano teórico, o que em termos de efetividade não assegura nenhum tipo de proteção contra intervenções antrópicas impactantes que possam trazer efeitos adversos ao ambiente.

Pôde-se verificar que as medidas tomadas por parte do Estado são pontuais e não sistemáticas, o que corrobora a hipótese inicialmente levantada.

\section{REFERÊNCIAS BIBLIOGRÁFICAS}

ALBUQUERQUE, Edu Silvestre de. Os donos da terra e do crédito público nos campos meridionais brasileiros (o uso dos fundos públicos do BRDE pela elite campeira do Pampa Gaúcho e dos Campos Gerais Paranaenses). 2007. Tese (Doutorado em Geografia). Programa de Pós Graduação em Geografia, UFSC, Florianópolis.

BRASIL. Decreto número 4.340, de 22 de agosto de 2002. Disponível em: < http:/ / www.planalto.gov.br/ ccivil_03/decreto/2002/d4340.htm>. Acesso em: 29 de janeiro de 2013.

BRASIL. Sistema Nacional de Unidades de Conservação. 2000. Disponível em: <www.planalto.gov.br/ ccivil_03/leis/L9985.htm>. Acesso em: 26 de setembro de 2012.

CARMO, Marta Regina Barrotto do. Caracterização fitofisionômica do Parque Estadual do Guartelá, município de Tibagi, Estado do Paraná. 2006. Tese (Doutorado em Ciências Biológicas). UNESP, Rio Claro.

CUNHA, Luís Henrique; COELHO, Maria Célia Nunes. Política e gestão ambiental. In: CUNHA, S. B.; GUERRA, A. J. T. A questão ambiental: diferentes abordagens. 5. ed. Rio de Janeiro: Bertrand Brasil. 2009. p. $43-80$.

DIEGUES, Antonio Carlos. Etnoconservação da natureza: enfoques alternativos. In: DIEGUES, A. C. Etnoconservação: novos rumos para a proteção da natureza nos trópicos. 2 ed. São Paulo: Annablume/ Nupaub/Hucitec, 2000. p. 01-46.

FERREIRA, Leila da Costa. A política ambiental no Brasil. In: MARTINE, G. (Org.) População, meio ambiente e desenvolvimento: verdades e contradições. 2. ed. Campinas: Editora da Unicamp. 1996. p. 171-182.

HASSLER, Márcio Luiz. A dinâmica das unidades de conservação na região metropolitana de Curitiba. RA'E GA, n. 12, p. 135-143, 2006.

LIMA, Gustavo Ferreira da Costa. A institucionalização das políticas e da gestão ambiental no Brasil: avanços, obstáculos e contradições. Desenvolvimento e Meio Ambiente, n. 23, p. 121-132, jan./jun. 2011.

MAACK, Reinhard. Notas preliminares sobre clima, solos e vegetação do Estado do Paraná. Curitiba: Arquivos de Biologia e Tecnologia, vol. 2, 1948.

MARCONI, Marina de Andrade; LAKATOS, Eva Maria. Fundamentos de metodologia científica. 7. ed. São Paulo: Atlas, 2010.

MELO, Mário Sérgio de. 2000. Canyon do Guartelá. In: SCHOBBENHAUS, Carlos; CAMPOS, Diógenes de Almeida; QUEIROZ, Emanuel Teixeira; WINGE, Manfredo; BERBERT-BORN, Mylène. Sítios Geológicos e Paleontológicos do Brasil. Disponível em: <http:// www.unb.br/ig/sigep/sitio094/sitio094.htm> Acesso em: 31 de agosto de 2011. 
MELO, Mário Sérgio de; MENEGUZZO, Isonel Sandino. Patrimônio natural dos Campos Gerais do Paraná. In: DITZEL, Carmencita de Holleben Mello; LÖWEN SAHR, Cicilian Luiza. Espaço e Cultura: Ponta Grossa e os Campos Gerais. Ponta Grossa: Editora da UEPG, 2001. p. 415-428.

MENEGUZZO, Isonel Sandino. Políticas ambientais para a conservação da natureza nos parques estaduais dos Campos Gerais do Paraná. 2013. Tese (Doutorado em Geografia). Programa de Pós-Graduação em Geografia, UFPR, Curitiba.

MINISTÉRIO DO MEIO AMBIENTE. Portaria número 217, de 19 de dezembro de 2002. Disponível em: <www.mma.gov.br>. Acesso em: 12 de setembro 2011.

MINISTÉRIO DO MEIO AMBIENTE. Portaria número 37, de 17 de fevereiro de 2004. Disponível em: <www.mma.gov.br>. Acesso em: 15 de setembro 2011.

MORAES, Antonio Carlos Robert. Meio ambiente e ciências humanas. 3. ed. São Paulo: Hucitec, 2002.

MOREIRA, Jasmine Cardozo; ROCHA, Carlos Hugo. Unidades de Conservação dos Campos Gerais. In: Melo, Mário Sérgio de; Moro, Rosemeri Segecin; Guimarães, Gilson Burigo. Patrimônio Natural dos Campos Gerais do Paraná. Ponta Grossa: Editora UEPG, 2007. p. 201-212.

PARANÁ. Decreto número 5.767, de 05 de junho de 2002. Disponível em: <http:/ / www.uc.pr.gov.br/ modules/conteudo/conteudo.php?conteudo=26>. Acesso em: 21 de setembro de 2011.

PARANÁ. Decreto estadual número 2.329, de 24 de setembro de 1996. Disponível em: <http://www. uc.pr.gov.br/modules/conteudo/conteudo.php?conteudo=26> .

Acesso em: 17 de setembro de 2011.

PARANÁ. Decreto número 6.351, de 23 de fevereiro de 1979. Disponível em: <http:/ / www.uc.pr.gov.br/ modules/conteudo/conteudo.php?conteudo=26>. Acesso em: 29 de setembro de 2011.

PARANÁ. Decreto número 1.527 de 02 de outubro de 2007. Disponível em: <http:/ / www.uc.pr.gov.br/ modules/conteudo/conteudo.php?conteudo=26>. Acesso em: 17 de setembro de 2011 .

PARANÁ. Decreto estadual número 1.528, de 02 de outubro de 2007. Disponível em: <http://www. uc.pr.gov.br/modules/conteudo/conteudo.php?conteudo=26>. Acesso em: 07 de setembro de 2011.

PARANÁ. Lei número 4.170, de 22 de fevereiro de 1960. Disponível em: <http://www.uc.pr.gov.br/ modules/conteudo/conteudo.php?conteudo=26>. Acesso em: 23 de setembro de 2011 .

PARANÁ. Lei número 1.292, de 10 de fevereiro de 1953. Disponível em: <http://www.uc.pr.gov.br/ modules/conteudo/conteudo.php?conteudo=26>. Acesso em: 17 de agosto de 2011.

PARANÁ. Lei número 1.232, de 27 de março de 1992. Disponível em: <http://www.uc.pr.gov.br/ modules/conteudo/conteudo.php?conteudo=26>. Acesso em 26 de setembro de 2011 .

PARANÁ. Portaria $\mathbf{n}^{0}$ 143, do dia 30 de julho de 2002. Disponível em: <http://www.uc.pr.gov.br/ modules/conteudo/conteudo.php?conteudo=26>. Acesso em: 28 de setembro de 2011.

PARANÁ. Portaria número 178, de 31 de agosto de 2004. Disponível em: <http://www.uc.pr.gov.br/ modules/conteudo/conteudo.php?conteudo=26>. Acesso em: 17 de setembro de 2011 .

PARANÁ. Portaria número 24, de 02 de março de 2009. Disponível em: <http://www.uc.pr.gov.br/ modules/conteudo/conteudo.php?conteudo=26>. Acesso em 29 de setembro de 2011 .

PHILIPPI JUNIOR, Arlindo; BRUNA, Gilda Collet; SILVEIRA, Vicente Fernando. Políticas públicas e desenvolvimento sustentável. In: PHILIPPI JUNIOR, Arlindo; ALVES, Alaor Café. Curso interdisciplinar de direito ambiental. Barueri: Manole, 2005. p. 789-810.

SAINT-HILAIRE, Auguste de. Viagem a Curitiba e província de Santa Catarina. Tradução de Regina Regis Junqueira. Belo Horizonte: Ed. Itatiaia, 1978.

SANTOS, Francisco Marques dos. (Org.) Diário da visita à Província do Paraná. Ponta Grossa, Editora da Universidade Estadual de Ponta Grossa, 2008.

SOUZA, Ana Cristina Augusto de. A evolução da política ambiental no Brasil do século XX. Revista de Ciência Política. n. 26. dez. 2005. 
TAKEDA, Adalberto Koodi; MATTOSO TAKEDA, Inês Janete; FARAGO, Paulo Vitor. Unidades de Conservação da Região dos Campos Gerais, Paraná. Revista Publicatio UEPG. p. 57-78, 2001.

VALLEJO, Luiz Renato. Os parques e reservas como instrumentos do ordenamento territorial. In: ALMEIDA, Flávio Gomes de; SOARES, Luiz Antônio Alves. Ordenamento territorial: Coletânea de textos com diferentes abordagens no contexto brasileiro. Rio de Janeiro: Bertrand Brasil, 2009. p. 157-193.

VELOSO, Henrique Pimenta; RANGEL FILHO, Antonio Lourenço Rosa; LIMA, Jorge Carlos Alves. Classificação da vegetação brasileira, adaptada a um sistema universal. Rio de Janeiro: IBGE, 1991.

Recebido em 07-04-2013

Aceito para publicação em 25-03-2014 